\title{
ESTUDIOS
}

\section{Las empresas familiares: una caracterización empre- sarial y la tipología societaria de capital más adecuada}

\author{
José Manuel Serrano Cañas'
}

Resumen: Las empresas familiares representan el motor económico más relevante en la mayoría de los países de economía de mercado. Su enorme importancia macroeconómica ha originado el nacimiento de un movimiento de defensa de sus intereses. Sin embargo, falta por definir las directrices que configuran su tipología empresarial y societaria. El presente trabajo tiene como finalidad precisamente reflexionar acerca de la caracterización y tipología de las empresas familiares, tanto desde un punto de vista empresarial, como desde un punto de vista del Derecho de sociedades.

Palabras clave: empresa familiar, pyme, sociedad de responsabilidad limitada, stakeholder.

Fecha de recepción: 20 de marzo de 2014 .

Fecha de admisión definitiva: 22 de mayo de 2015.

Family businesses: a best corporative characterization and typology

Abstract: Family businesses are the most relevant economic engine in most of the countries of market economy. His huge macroeconomic importance has led to the birth of a movement to defend their interests.

\begin{abstract}
Les entreprises familiales: une caractérisation patronale et une typologie sociétaire de capitale plus adequate
\end{abstract}

Résumé: Les entreprises familiales représentent le moteur économique le plus éminent dans la majorité des pays d'économie de marché. Son énorme importance macroé-

1 Área de Derecho Mercantil, Facultad de Derecho, Universidad de Córdoba. 
However, it remains to define the guidelines that shape their business and corporate type. This paper aims precisely reflect on the characterization and typology of family businesses, both from a business point of view and from the point of view of company law.

Keywords: family businesses, SME, limited liability company, stakeholder. conomique a provoqué la naissance d'un mouvement de défense de leurs intérêts. Cependant, il nous manque la definition des directrices qui configurent sa typologie patronale et sociétaire. Cetravail précisément a pour but la réfléxion à propos de la charactérisation et de la typologie des entreprises familiales, d'un point de vue patronal, ainsi que d'un point de vue du Droit de sociétés.

Mots-clés: entreprise familiale, PME, société à responsabilité limitée, stakeholder.

\section{Introducción}

En el momento actual se asiste a la consolidación de un verdadero movimiento de defensa de los intereses propios de un determinado modelo empresarial: las empresas familiares. Este lobby pro empresa familiar, cuya manifestación exterior más palpable se encuentra en la proliferación de cátedras e institutos de empresa familiar a lo largo y ancho de nuestro territorio nacional, reclama el reconocimiento y visualización del nuevo y preponderante papel desarrollado por este tipo de empresas en la realidad económica².

A decir verdad, no puede afirmarse con total rotundidad que las empresas configuradas y cualificadas por el carácter familiar de sus componentes ly por la preeminencia de la defensa de unos intereses distintos cuando no, acaso, contrapuestos a los meramente empresariales) supongan una invención propia de este momento histórico. Es más, ni siquiera puede afirmarse que la constitución de una empresa familiar se haga de forma querida y premeditada. Nadie funda "per se" una empresa familiar, sino que ésta aparece por regla general como algo connatural

\footnotetext{
2 Sirva como botón de muestra la celebración del Consejo Europeo de Santa María da Feira (19 a 20 de junio de 2000) en el que se elabora la denominada Carta Europea para la pequeña empresa donde, además de ofrecer una invitación a los distintos países miembros para que presenten una relación anual de actuaciones encaminadas a mejorar la gestión de las pequeñas y medianas empresas, expresamente se llama la atención acerca de la importancia tan radical de tales empresas en la economía europea, siendo enjuiciadas por el Consejo como la espina dorsal de la economía europea (...) una fuente primaria de creación de puestos de trabajo, así como un sector en el que fluyen las ideas empresariales.
} 
o propio de la antropología social-familiar de nuestra Cultura³. Lo habitual es que la empresa comience su actividad en el mercado sin tener conciencia de su tipología familiar. Este carácter familiar se adquiere, empero, por el acaecer en la persona del fundador de una vicisitud personal, ajena a la actividad empresarial: su vinculación con otras personas mediante el establecimiento de relaciones de parentesco. De tal suerte que en caso de que la empresa prospere puede aparecer en los descendientes del fundador el deseo de suceder y continuar en y con la gestión de la empresa y hacer de ella la fuente primordial de la riqueza patrimonial familiar. Se trata, pues, de un fenómeno natural y corriente, propio de cualquier economía de mercado y de cualquier tiempo histórico ${ }^{4}$.

Asimismo, tampoco se puede manifestar de forma gratuita que las empresas familiares hayan estado completamente carentes de tratamiento jurídico propio y diferenciado. Se pueden traer a colación numerosas instituciones jurídico-mercantiles arraigadas históricamente en nuestro ordenamiento jurídico que han surgido para dar respuesta histórica a realidades empresariales de índole familiar, como es el caso de la sociedad (general) colectiva. Este tipo societario, como es bien sabido, hunde sus raíces en la comunidad familiar medieval y en la continuación por los hijos de los negocios del padre fallecido 5 . La continuación de la explotación del negocio mercantil del padre difunto por parte de sus descendientes da lugar al nacimiento de una especie de comunidad familiar ("societas duorum fratrum") que más tarde se transforma en una verdadera comunidad de trabajo que, si bien ya no necesariamente ha de conformarse entre personas ligadas por lazos sanguíneos, subsiste empero con un fortísimo elemento personalista, de confianza mutua, de compañerismo ("ad unum panem et vinum" $)^{6}$.

\footnotetext{
${ }^{3}$ En expresión de Alonso EsPinOSA (2012), p. 3.

${ }^{4}$ El origen histórico del sistema económico actual guarda una estrecha relación con la empresa de carácter familiar. Se puede citar, por ejemplo, el caso de los Függer, banqueros de Carlos $\vee$ y Felipe ll en el siglo XVI. En Inglaterra, en la segunda mitad del siglo XVII y en la primera mitad del XVIII, la familia Lloyd comenzó su actividad como aseguradores de barcos, sociedad que existe en la actualidad. Los nombres de Wilkinson, Siemens, Bosch, Krupp, Rockefeller, Rotschild, Ford están unidos en su origen a la creación de grandes compañías controladas por grupos familiares. No obstante, actualmente en el seno de numerosas empresas multinacionales coexisten aún grupos familiares, descendientes de los fundadores, los cuales ejercen un control muy importante sobre su gestión (como los Agnelli en Fiat, B. Gates en Microsoft, etc.). De Aguiar, (1998), p. 21.
}

${ }^{5}$ GIRÓN TENA (1976), pp. 373 ss.

${ }^{6}$ GarRIGUes (1976), p. 352 
La nota de actualidad estriba, empero, en la toma de conciencia de sus dimensiones macroeconómicas. El examen atento a esta tipología empresarial pone de manifiesto que la empresa familiar constituye, sin duda alguna, el motor económico más relevante en la mayoría de los países de economía de mercado, conforma el principal actor del tejido productivo empresarial y el principal creador de riqueza. En los Estados Unidos, entre el $80 \%$ y el $90 \%$ de las empresas presentan carácter familiar, lo que representa aproximadamente el $50 \%$ de su PIB, genera el $60 \%$ de los puestos de trabajo. En la Unión Europea, existen aproximadamente 17 millones de empresas familiares, que dan trabajo a casi 100 millones de personas (esto significa que más del $60 \%$ de todas las empresas de la Unión Europea son familiares, incluyendo el $25 \%$ de las 100 empresas europeas de mayor dimensión económica). En España, las empresas familiares representan el 85\% sobre el total de las empresas españolas, con 2,9 millones de establecimientos (constituyen el $26 \%$ de las 1000 empresas más importantes del país); cuentan con más de 13,9 millones de trabajadores (el 70\% del mercado de trabajo); generan el $70 \%$ del PIB español, al tiempo que realizan el $60 \%$ de las exportaciones españolas ${ }^{7}$.

El mayor grado de conocimiento de la magnitud empresarial representada por las empresas familiares origina este movimiento de defensa. Fruto de ello, comienzan a reclamar para sí la trasposición del pensamiento relativo a la buena administración de las grandes corporaciones cotizadas, cuyas disfunciones de gobernanza han dado tanto de qué hablar en décadas anteriores merced al movimiento de la "corporate governance", así como la introducción de cuantas medidas sean necesarias para la solución de los dos grandes problemas que les afectan: la gobernanza empresarial y el cambio generacional ${ }^{8}$.

\footnotetext{
${ }^{7}$ MINISTERIO DE ECONOMía (2003), p. 9; Estadísticas del Instituto de la Empresa Familiar publicadas en su página web (http://www.iefamiliar.com/web/es/cifras ief.html). A su vez, CoRONA Ramón (2005), p. 26.

${ }^{8}$ De este reclamo a los poderes públicos por parte del lobby "empresa familiar" de la defensa de sus intereses, deriva la promulgación del Real Decreto 171/2007, de 9 de febrero, regulador de la publicidad de los protocolos familiares (en adelante, RD 171/2007). Por medio de este Real Decreto, se intenta abrir el Registro mercantil a los protocolos familiares, intentando otorgarle la eficacia jurídica registral (o erga omnes), así como configurarlo como una verdadera prestación accesoria. A su vez, en lo atinente al problema sucesorio, los arts. 1056.2 y 1271.2 CC fueron fruto de una intensa modificación, merced a la Disposición Final $1^{\circ}$ de la Ley $7 / 2003$, de 1 de abril, de la Sociedad Limitada Nueva Empresa. Esta reforma del Derecho sucesorio está encaminada a mejorar el funcionamiento de la partición hecha por el testador con vistas a preservar indivisa una explotación económica o bien mantener el control de una sociedad de capital o grupo de éstas. Se pretende así otorgar un mayor grado de certeza jurídica a la planificación sucesoria del empresario-fundador, titular de la empresa, articulando jurídicamente la posibilidad de atribuir a uno o varios herederos previamente elegidos por el fundador los activos empresariales o las participaciones o acciones de la sociedad mercantil que dé forma a la empresa familiar.
} 
El presente trabajo se propone trazar las directrices que configuran la tipología empresarial y societaria de este tipo empresarial. Para ello, se partirá de la construcción de un concepto económico y jurídico válido, a partir del cual se pueda comprender las fortalezas y debilidades de esta tipología empresarial, así como construir la configuración jurídico-societaria más óptima para la satisfacción de los intereses en juego. En este sentido, conviene advertir que el análisis de la tipología societaria más adecuada se va a centrar en la opción por organizar la empresa a través de sociedades mercantiles $y$, dentro de ellas, mediante las sociedades de capital.

\section{Concepto de empresa familiar}

\section{I. La confusión entre empresa familiar y PYME}

Aunque la empresa familiar constituya un modelo empresarial individualizado, la determinación de sus notas conceptuales no está exenta de una enorme dificultad. De hecho, en Europa se han identificado hasta 90 definiciones distintas de empresa familiar?. Se suele identificar con cierta frecuencia empresa familiar con pequeña y mediana empresa (PYME), lo que constituye una importante fuente de errores.

El concepto de PYME viene establecido por la Recomendación de la Comisión Europea 2003/361/CE, de 6 de mayo. En ella se distingue entre microempresa, pequeña empresa y mediana empresa. Esta última, la mediana empresa, es aquella que cuenta con menos de 250 trabajadores y su volumen de negocios anual no excede de 50 millones de euros o su balance general anual no excede de 43 millones de euros. Por pequeña empresa se entiende la que da ocupación a menos de 50 personas y cuyo volumen de negocios anual o cuyo balance general anual no supera los 10 millones de euros. Y, por último, una microempresa es aquella en la que trabajan menos de 10 personas y cuyo volumen de negocios anual o cuyo balance general anual no supera los 2 millones de euros ${ }^{10}$.

\footnotetext{
${ }^{9}$ Rojo Ramírez/DiéGuez Soto/López Delgado (2011), p. 54.
}

${ }^{10}$ A tales factores hay que añadir, por último, una tercera cualidad para caracterizar una empresa como de pequeña o media dimensión: la noción de independencia. En efecto, la definición de PYME acogida en la Recomendación de 6 de mayo de 2003 (que entró en vigor el 1 de enero de 2005) clarifica esta tipología empresarial. Esta Recomendación lleva a cabo una división en tres tipos de empresas en función del tipo de relación que mantienen con otras en cuanto a participación en el capital, 
En términos generales, entre empresa familiar y pyme existe una amplia zona de intersección, puesto que la mayor parte de las empresas familiares son de pequeña y mediana dimensión ${ }^{11}$. En efecto, por norma general las empresas familiares no sólo nacen como PYME, sino que se mantienen así a lo largo de su vida. Sin embargo, nada impide que, con el tiempo, puedan adquirir un enorme volumen de negocio. En efecto, ni todas las PYME son empresas familiares, ni todas las empresas familiares son de pequeñas y medianas dimensiones. Existen grandes compañías, incluso cotizadas, en manos de un núcleo familiar que operan en el mercado como verdaderas empresas familiares. Los datos reales indican que existen empresas

derecho de voto o derecho de ejercer una influencia dominante. Se distingue así entre las empresas autónomas; las empresas asociadas; y las empresas vinculadas.

Las empresas autónomas son, con mucho, el caso más frecuente dentro del mundo de la pequeña y mediana empresa. Se trata de cualquier empresa que no entra dentro de ninguno de los otros dos tipos de empresas (asociadas o vinculadas). Una empresa es autónoma si no posee una participación igual o superior al $25 \%$ de otra empresa; no tiene un $25 \%$ o más de su capital social en manos de otra empresa u organismo público o, bien, de forma conjunta por varias empresas vinculadas u organismos públicos, salvo algunas excepciones; no tiene cuentas consolidadas y no figura en las cuentas de una empresa que tenga cuentas consolidadas y no es, por tanto, una empresa vinculada. Una empresa puede, no obstante, recibir la calificación de autónoma, aunque se alcance o supere el límite del $25 \%$ cuando estén presentes determinadas categorías de inversores, como los que realizan una actividad regular de inversión en capital riesgo (inversores providenciales o "business angels").

Son empresas asociadas aquellas que establecen asociaciones financieras importantes con otras empresas, sin que una ejerza un control efectivo directo o indirecto sobre la otra. Son asociadas las empresas que no son autónomas pero que tampoco están vinculadas entre sí. Una empresa estó asociada a otra si posee una participación comprendida entre el 25 y el $50 \%$ de dicha empresa; la otra empresa posee una participación de entre el $25 \%$ y menos del $50 \%$ de la primera; la primera no tiene cuentas consolidadas en las que figure la otra y no figura por consolidación en las cuentas de aquélla o de una empresa vinculada a aquélla.

Por último, las empresas vinculadas se asimilan a la situación económica de aquellas empresas que forman parte de un grupo, por el control directo o indirecto de la mayoría del capital o de los derechos de voto (incluso a través de acuerdos o, en algunos casos, mediante personas físicas accionistas), o por la capacidad de ejercer una influencia dominante sobre una empresa. Se trata, pues, de casos menos frecuentes que se distinguen en general de forma muy clara de los dos tipos precedentes. A fin de evitar a las empresas problemas de interpretación, la Comisión Europea definió este tipo de empresas recogiendo las condiciones establecidas en el artículo 1 de la Directiva 83/349/CEE del Consejo relativa a las cuentas consolidadas. Así pues, una empresa es conocedora de su estado de vinculación, por norma general de modo inmediato, cuando con arreglo a esta Directiva viene obligada a formular cuentas consolidadas o si figura por consolidación en las cuentas de otra empresa.

1 Sirva como botón de muestra de las similitudes entre PYME y empresas familiares la gestión personalizada de las PYME. De manera análoga a lo que sucede con las empresas familiares, la gestión de PYME se suele concentrar en los socios fundadores. Lo que es válido incluso en los casos en los que las PYME puedan tener una amplia base subjetiva. 
familiares que están desempeñando actualmente un papel muy significativo entre las más importantes y grandes compañías de los países de nuestro entorno ${ }^{12}$. En cualquier caso, toda empresa familiar (cualquiera que sea su dimensión), viene afectada por los mismos problemas típicos: los conflictos entre padres e hijos, la posible rivalidad entre hermanos, las condiciones en las que deben ser integrados en el seno de la empresa los diversos miembros de la familia y, de forma especial, la previsión y preparación del momento sucesorio.

\subsection{El modelo de los tres círculos}

En el mundo económico-empresarial, la empresa familiar constituye un modelo de empresa individualizado y distinto del resto de empresas. La expresión empresa familiar encierra y oculta en su interior un concepto metajurídico, de naturaleza sociológica, empresarial yeconómica ${ }^{13}$. En este sentido, parece existir cierto consenso a la hora de considerar que, al menos desde el punto de vista teórico, empresa familiar es aquella en donde convergen y conviven tres factores: la propiedad (esto es, la titularidad de la empresa o de la mayoría del capital por parte de una unidad familiar), la participación activa de la familia en la gestión de la empresa y el hecho y la tendencia a la duración en el tiempo como sociedad familiar, esto es, más allá de la primera o segunda generación.

Estos tres factores (familia, propiedad y gestión, dirección o trabajo) se encuentran en la base del modelo económico más importante que se ha elaborado para sistematizar y conceptuar a las empresas familiares. Nos referimos al sistema o modelo de los tres círculos diseñado por los profesores TAGIURI y DAVIS, que ha sido objeto de un posterior desarrollo por los profesores WARD y LANSBERG ${ }^{14}$. Según

\footnotetext{
${ }^{12}$ Así, por ejemplo, en los Estados Unidos, Gran Bretaña o Alemania se considera que entre el 50\% y el $60 \%$ de las 1.000 principales compañías son familiares (pudiendo citar, en EE.UU., a Bechtel, Levi Strauss, Marriott, New York Times, Washington Post; o, en Europa, por ejemplo, a Hennes and Mauritz, Fita, Hermès, Peugeot, BMW, Heineken, Ermenegildo Zegna, Salvador Ferragano, Ferrovial Planeta, Nutrexpa, Cortefiel, Zara, Mango). Cerdá Alvero (2004), p. 97; Alonso Espinosa (2012), p. 5.

${ }^{13}$ Iglesias Prada, (1994), p. 5418; Rodríguez Artigas (2003), p. 17.

14 Tagiuri/Davis (1982), pp. 329-339; Gersick/Davis/Maccollom/Lansberg (1998); Sánchez-Crespo CASANOVA (2000), p. 8. Antes de la elaboración del modelo de los tres círculos y partiendo de la teoría general de los sistemas (conceptuada por el biólogo alemán LUDWIG VON BARTALANFFY), contábamos con una teoría de empresa familiar creada en el seno de la Universidad de Harvard basada en dos sistemas o círculos concéntricos e interrelacionados: la familia propietaria y la gestión o dirección de la empresa. Cada uno de estos dos círculos presenta sus propias normas, reglas de admisión, estructuras
} 
este modelo, en la empresa familiar confluyen tres grupos o núcleos de personas interesadas ("stakeholders") en ella y que se relacionan entre sí. En concreto, se trata de los siguientes:

En primer lugar, el núcleo familiar en sí mismo considerado, independientemente del lugar que ocupen sus miembros en la empresa o en la sociedad mercantil que sirva de estructura jurídica a aquella, esto es, sin tomar en consideración el hecho de que trabajen o no en la empresa o sean o no titulares de las participaciones o acciones societarias. La familia comprendida así de forma autónoma, tiende a perseguir la consecución y el mantenimiento de un cierto nivel de armonía en el seno de las relaciones familiares, junto al desarrollo personal (económico y moral) de cada uno de sus miembros, sin tomar en consideración sus mayores o menores aptitudes para regir y gestionar la empresa familiar. Para la familia, la empresa y la sociedad son meros instrumentos enderezados al logro del fin último que le es propio: el bienestar de la familia y de cada uno de sus miembros.

En segundo lugar, el núcleo de la propiedad de la empresa (esto es, los titulares de la empresa o los accionistas o partícipes de la sociedad mercantil que hayan servido para la subjetividad jurídica necesaria de la empresa familiar), cuyos miembros, a su vez, pueden pertenecer o no al núcleo familiar o al núcleo empresarial.

de valores y organización. Los conflictos aparecen cuando la base subjetiva empieza a estar compuesta por personas que desarrollan roles obligacionales en ambos círculos (por ejemplo, en el caso habitual de ser progenitor y al mismo tiempo director de la empresa). El reto fundamental y común a todas las empresas familiares, por lo tanto, estriba en la elaboración de estrategias capaces de satisfacer coetáneamente los intereses de ambos subsistemas.

A partir de este modelo dualista se construyó el modelo de los tres círculos. Los profesores TAGIURI y DAVIS consideraron, en efecto, que la gran variedad de empresas familiares existentes estaría mejor representada si el subsistema de gestión se dividiese en otros dos círculos, donde se diferenciase entre la gestión y la propiedad de la empresa. De esta forma, cabría la posibilidad de contemplar los supuestos de propietarios no gestores, los propietarios y gestores y los que simplemente desempeñan el papel de simples gestores. Surge así el modelo de los tres círculos.

Este modelo ha sido recientemente completado añadiendo el factor temporal, o más concretamente, contemplando los ciclos vitales, las generaciones o estaciones que señalan la evolución de la familia empresaria y de la empresa familiar (nacimiento, expansión y madurez), lo que se debe al profesor LEVINSON. Los tres subsistemas entre sí relacionados y a su vez contemplados durante las eras o generaciones familiares por las que discurre la familia empresaria y la empresa familiar, configurando el llamado modelo evolutivo tridimensional. Fue el profesor WARD quien estudió la evolución temporal de la propiedad familiar de la empresa. Ésta pasa por una primera fase de iniciación del empresario, seguida de una segunda de economía unida (esto es con los hijos, con hermanos, con socios profesionales) y, por último, aquella del consorcio de los primos, en donde se hace necesaria la creación de la figura del Consejo de familia y del protocolo familiar, con la necesaria delimitación de los órganos sociales (esto es, la Junta general y el órgano de administración). 
Este grupo de "stakeholders" (y, a su vez, de "shareholders") persigue, como no podría ser de otra manera, además de cierto nivel de armonía ente los accionistas mayoritarios y minoritarios, una gestión del patrimonio societario encaminada a aumentar el valor de su inversión o, al menos, a mantenerlo (haciéndolo, eso sí, compatible con el posible reparto de beneficios) y, en menor medida, cierta estabilidad o mejora del rendimiento económico de la empresa y de su posición competitiva en el mercado.

En tercer lugar, el núcleo de los trabajadores de la empresa, que pueden o no formar parte de la familia, así como ser o no accionistas o socios partícipes. Obviamente, el interés perseguido por este último grupo se concreta, fundamentalmente, en la conservación (o mejora) de su puesto de trabajo y de sus condiciones laborales, junto con la consecución de la máxima eficacia empresarial, la mejora del clima organizativo y el continuo desarrollo de la empresa.

Las relaciones entre estos tres núcleos o círculos de "stakeholders" permiten individualizar siete grupos distintos de situaciones o de subgrupos de interesados, cada uno con su propia idiosincrasia e intereses, frecuentemente divergentes y conflictivos $^{15}$. Así, tendremos: $1^{\circ}$ ) miembros de la familia que no son propietarios ni trabajadores en la empresa; $2^{\circ}$ ) propietarios de la empresa que no son miembros de la familia ni trabajan en la empresa; $3^{\circ}$ ) trabajadores de la empresa que no son miembros de la familia ni propietarios; $4^{\circ}$ ) miembros de la familia que son propietarios y no trabajan en la empresa; $5^{\circ}$ ) miembros de la familia que no son propietarios y trabajan en la empresa; $6^{\circ}$ ) propietarios que no son miembros de la familia y trabajan en la empresa; $y, 7^{\circ}$ ) miembros de la familia que son propietarios y trabajan en la empresa.

A estos siete grupos hay que añadir un octavo, compuesto por aquellos sujetos con intereses en la empresa pero que no pertenecen a ninguno de los miembros de los tres círculos, esto es, otros grupos de interesados -"stakeholders"- tales como

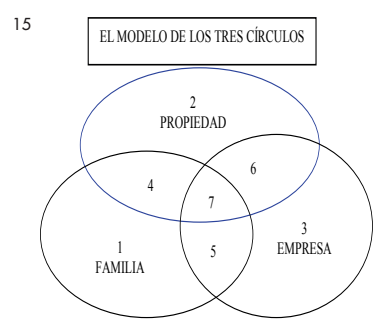

Elaboración propia. 
los clientes, proveedores, intereses públicos de la comunidad política donde esté arraigada la empresa familiar, etc. ${ }^{16}$.

\subsection{La empresa familiar como modelo de integración de intereses de "stakeholders"}

La clave del éxito de la gestión de las empresas familiares estriba, por tanto, en la consecución del deseado y difícil equilibrio entre los distintos intereses (y la ética práctica que direccionan el comportamiento económico) de los diversos grupos de "stakeholders" que confluyen en las empresas familiares. De forma sintética, se pueden reducir a dos los intereses y valores que están en juego y que, además, son diametralmente contrapuestos: los objetivos empresariales subordinados a la eficiencia económica, frente a los propios de la familia propietaria regidos por la solidaridad y lealtad entre los miembros de la familia. La existencia de esta tensión dialéctica entre estos dos sistemas de valores y de comportamientos diferentes se manifiesta en todos los ámbitos decisionales de la empresa. Así, los gestores de empresas familiares deben determinar el tratamiento (siempre diferenciado) que merecen aquellos miembros de la familia que trabajan en el seno de la empresa o que ocupan cargos directivos con respecto al resto del personal -condicionando la posibilidad de promoción interna-. A su vez, deberán resolver uno de los problemas específicos y propios de las empresas familiares. Nos referimos a la individualización de la política de contratación de la empresa. En este sentido, deberá velar no sólo por la captación de aquellos profesionales más capacitados para cada puesto de trabajo, sino además, por la integración en la empresa de los distintos miembros de la familia, especialmente cuando el grupo familiar aumenta con las sucesivas y nuevas generaciones. Por otra parte, teniendo en cuenta que la vida de la empresa puede (o al menos debería) ser superior a la de su propietario-fundador, además, será necesario elegir el momento más oportuno de la sucesión o de la venta de la empresa; discernir y elegir quién va a suceder al fundador, así como la redistribución del poder en la empresa entre los miembros

${ }^{16}$ Sobre la base de estos tres elementos, el European Group of Owner Managed and Family Enterprises (GEEF) aprobó el 27 de mayo de 2008 una definición genérica de empresa familiar que incluye los siguientes elementos: $1^{\circ}$.- Que la familia pueda ejercer el control accionarial de la compañía, bien sea por poseer la mayoría de los votos, o por su posibilidad de ejercer una influencia decisiva sobre los aspectos fundamentales del gobierno corporativo; $2^{\circ}$.- tener una presencia relevante en los órganos de gobierno corporativo de la compañía (por regla general, el Consejo de administración); $3^{\circ}$.- la participación directa de un miembro de la familia en la gestión de la empresa a su máximo nivel. Roso Ramírez/DiéGuez Soto/López Delgado, (2011), p. 55. 
y ramas familiares tras la sucesión del fundador ${ }^{17}$. Con todo, familia y empresa, a pesar de perseguir fines totalmente diferentes, cuando no opuestos, pueden ser permeables entre sí.

La empresa familiar se nos presenta así como un organismo vivo y dinámico, un sistema complejo, compuesto por un conjunto de subsistemas interdependientes, con la finalidad de ofrecer el máximo efecto sinérgico capaz de generar la empresa familiar, como la realidad y el análisis económico han demostrado ${ }^{18}$.

En suma, podemos adherirnos a aquella construcción doctrinal que aboga por defender que las empresas familiares se cualifican por la forma de ejercicio de la gobernanza empresarial, puesto que introyectan en la racionalidad de la gestión empresarial, otros criterios de actuación que proceden de una fuente axiológica distinta. Sin embargo, es preciso añadir a estas variables cuantificables un argumento cualitativo, que dota a la empresa de un carácter verdaderamente familiar. Dicha variable reside en tener a la continuidad generacional como objetivo estratégico de la empresa, basada en el deseo conjunto de fundadores y sucesores de mantener el control de la propiedad, el gobierno y la gestión de la empresa en manos de la familia ${ }^{19}$. En realidad, el concepto de empresa familiar no es dicotómico, esto es, las empresas ni son familiares ni no lo son, sino que sino que son familiares en mayor o menor grado. Se trata, pues, de una variable gradual, que depende caso por caso de las circunstancias en que se desenvuelven (tales como la propiedad, la gestión, la consciencia de pertenecer a una familia, la incorporación de las nuevas generaciones, etc.).

\subsection{Conclusión: el interés social-empresarial familiar como criterio definitorio de la empresa familiar}

A la vista de lo expuesto, cabe afirmar que la empresa familiar se presenta como una institución de carácter económico-empresarial cuya categorización doctrinal ha sido llevada a efecto por una elaboración propia de la ciencia económica y empresarial, que da respuesta a una determinada realidad fáctica o tipo empresarial: aquella en la que está presente, impregnando todo el comportamiento

17 De Aguiar (1998), pp. 19-23.

${ }^{18}$ Garkido de Palma (2005), pp. 69-70.

19 Astrachan/Klein/smyrnios (2000), pp. 51 y ss.; Chua/Chrisman/Sharma (1999), pp. 24 y ss.; Birley (2001), pp. 63 y ss.; KOTeY (2005), pp. 5 y ss. 
racional-económico de la gestión empresarial, una unidad o núcleo familiar. La empresa familiar (que no familia empresaria) ${ }^{20}$ es, por tanto, aquélla en la que las estrategias o políticas gestoras están imbuidas por criterios subjetivos, de índole familiar, de ayuda al sustrato familiar sobre el que descansa, pivota y se construye la empresa, y que podríamos denominar como interés social-empresarial familiar. La empresa familiar es, en definitiva, un modelo de empresa caracterizado por la defensa de este interés social-empresarial familiar. Por mor de la defensa de este interés superior, al que se subordinan y direccionan todas las decisiones empresariales, se produce la inserción y la armonía entre las relaciones familiares que vinculan a sus propietarios como un elemento más ante la organización, y el gobierno de la empresa sobre la que recae el derecho de propiedad o los derechos de control de aquéllos sobre la misma ${ }^{21}$.

Por consiguiente, para conceptuar a la empresa familiar desde un punto de vista económico habrá que utilizar otros criterios distintos al mero dato cuantitativo de la cuota participativa de la familia en la propiedad o en la composición del "management". Tales criterios numéricos son frecuentemente motivo de conclusiones erróneas, por dar una percepción alejada de la realidad y por la imposibilidad de cuantificar, de ponderar y de mensurar intangibles familiares. Y es que, lo que cualifica a una empresa como familiar no es un determinado porcentaje de capital social en manos de la familia o la composición numérica de la gerencia.

Habrá una empresa familiar cuando ésta venga influenciada por la existencia de una familia o por un vínculo familiar $y$, de forma fundamental, cuando la empresa tenga como finalidad última la satisfacción de un interés social-empresarial familiar concreto, nacido por la existencia de vínculos de parentesco entre los propietarios o titulares del control de la empresa: el interés en la conservación de la propiedad de la empresa o en la de sus instrumentos jurídicos de control entre quienes mantienen entre sí relaciones de parentesco familiar y el interés en el ejercicio del gobierno de la empresa por parte de representantes de los miembros de la familia titular

${ }^{20}$ En efecto, una familia empresaria es aquélla en la que alguno o varios de sus miembros cuentan con vocación empresarial y que, en consecuencia, desarrollan actividades empresariales pero con la finalidad de satisfacer un interés social familiar, superior al propio e individual de cada uno de los miembros de la familia y de cada actividad empresarial individualmente considerada. Ahora bien, con toda probabilidad casi todo empresario estará inserto en una realidad familiar. Sin embargo, no debe identificarse la existencia de empresas gestionadas en interés de una familia (empresas familiares), con familias o miembros de éstas que desarrollen actividades empresariales (familias empresarias). Así, no toda familia empresaria (con espíritu emprendedor) gestiona empresas familiares, aunque, por el contrario, toda empresa familiar se sustenta en la existencia de una familia empresaria.

${ }^{21}$ Alonso Espinosa (2012), p. 11. 
de su propiedad o contro| ${ }^{22}$. El caso más evidente se dará en aquella empresa en la que la familia puede controlar efectivamente las operaciones empresariales por poseer más del 50 de las cuotas del capital o porque sus miembros ocupan importantes posiciones en la gerencia empresarial o societaria. Pero, también en otros casos menos evidentes (en los que no se alcancen tales cuotas significativas de capital o de composición gerencial) puede existir una empresa familiar. Así acontecerá siempre que las operaciones de la firma estén influenciadas por motivos familiares, es decir, que las relaciones padre-hijo, hermano-hermana, parientes políticos y primos adquieren una incidencia significativa sobre el presente y el futuro de la organización ${ }^{23}$.

En suma, es este interés social-empresarial familiar, y no cualquier otro elemento empresarial u organizativo, el que da sustancia y fundamento a una empresa para adjetivarla como familiar ${ }^{24}$.

\section{Caracterización y problemática empresarial de las empresas familiares}

\section{I. Caracterización de la empresa familiar: ventajas y debilidades de la empresa familiar}

El carácter familiar de la empresa (esto es, el hecho de la existencia de una familia titular de una empresa o, al menos, titular de la mayoría de capital social que otorga el control de aquélla) le imprime un sistema de gestión que la diferencia del resto. Se puede afirmar que el modelo empresa familiar viene conformado a través de tres rasgos característicos ${ }^{25}$ :

\footnotetext{
${ }^{22}$ Alonso Espinosa (2012), p. 3.

${ }^{23}$ LEACH (1999), p. 22.

${ }^{24}$ Para el profesor ALONSO ESPINOSA (2012), pp. 11 y ss., de los dos elementos en los que se descompone este interés (familia y empresa) es sin duda el aspecto empresarial el que debe primar, constituyendo el centro y presupuesto de interés de los propietarios-familia. Las relaciones e intereses familiares, a modo de "desideratum", han de subordinarse frente a los intereses empresariales. La empresa ha de defenderse de los riesgos y amenazas que se derivan de los vínculos familiares.

${ }^{25}$ Fernández Gimeno (1999), p. 31; Couret (1993), pp. 9-20; Astrachan, Klein y Smyrnios (2000), pp. 47
} 
a) Un modo particular de ejercicio del poder económico. En las empresas familiares, al estar concentrado el poder económico en el seno de una familia (concretamente, como regla general, a manos del cabeza de familia), el poder económico se ejerce no según los parámetros de la pura racionalidad económica (en pos de la defensa única y unívoca de los intereses empresariales), sino en atención a los intereses de los miembros de su familia; lo que conlleva introyectar en el ejercicio del poder económico una racionalidad distinta $y$, acaso, contrapuesta a aquella;

b) Una percepción particular del riesgo y de la responsabilidad. Los recursos que se invierten en la empresa familiar pertenecen a la misma familia, lo que reduce la percepción del riesgo de los familiares que trabajan en ella. Además, con frecuencia, ante la aparición de dificultades económicas (o, incluso, de forma sintomática), suelen renunciar a la distribución de los beneficios a favor de la amplificación de la empresa, así como, asumir los débitos y las cargas de la empresa con el patrimonio no afectado;

c) Una amenaza estructural de su continuidad: normalmente la muerte del empresario avecina la extinción de la empresa (a diferencia de las empresas no familiares o societarias), de modo particular cuando nos encontramos en la segunda o en la tercera generación.

Estas características otorgan a las empresas gestionadas bajo el poder de una familia una serie de ventajas singulares que las fortalecen del resto de empresas. En efecto, una empresa familiar puede aportar un mayor sentido de integración y una motivación superior que el resto de empresas, así como una mayor capacidad de consagración y sacrificio, lo que conlleva un ahorro de costes y un aumento de ingresos superior respecto de las no familiares. Como indican los profesores

y ss.; ChUa, Chrisman y Sharma (1999), pp. 24 y ss. Asimismo, las empresas familiares se caracterizan por el desarrollo de buenas prácticas empresariales. Así, por ejemplo, suelen optar por la tradición y la continuidad en las futuras generaciones lo que conlleva una planificación a largo plazo de su labor empresarial. Sus productos y servicios suelen tener una mayor calidad. Por sus dimensiones, son empresas más flexibles y adaptables a las necesidades del mercado y de su entorno, puesto que la toma de decisiones se realiza con suma rapidez. Además, existe un buen ambiente laboral y un buen trato personal para con los clientes. Los valores de la familia se trasladan a la empresa, lo que se traduce, con frecuencia, en la implantación de políticas de responsabilidad social corporativa (a fin de salvaguardar el buen nombre de la familia). Los fundadores suelen ser trabajadores natos e incansables, con un nivel altísimo de austeridad. El capital social aportado, por tanto, no suele ser retribuido, esto es, apenas si se exigen reparto de dividendos, con un considerable ahorro en costes laborales, de administración y capital. 
NeUBAUER y LANK ${ }^{26}$, las empresas familiares obtienen mejores resultados que aquellas no familiares, en la medida en que gozan de cuatro tipos de ventajas: i) ventajas económicas, basadas en la separación de la función del accionista y la del gestor; ii), ventajas de gestión, dado el especial vínculo afectivo al proyecto empresarial que comporta la optimización en la toma de decisiones; iii) ventajas derivadas de la vocación de continuidad en la empresa, lo que genera expectativas de futuro; y iv) ventajas de visión a largo plazo, no estando sometidas a la maximización del rendimiento económico de la empresa, ni de la inversión en el plazo más breve posible, concentrándose en una estrategia de desarrollo empresarial a largo plazo.

No obstante las ventajas aludidas, el carácter familiar no las inmuniza completamente, puesto que adolecen de algunos comportamientos económicos que pueden ser altamente nocivos para la buena marcha empresarial ${ }^{27}$. En las empresas familiares coexisten tres elementos (la familia, la propiedad y el gobierno de la empresa) que suelen provocar tres órdenes de confusiones (confusión entre empresa y familia, entre empresa y accionariado y entre empresa y gestión familiar). Por desgracia, con demasiada frecuencia, en estas realidades empresariales se confunden los límites entre la familia y la empresa. Más concretamente, es fácil mezclar el patrimonio familiar del empresario con el patrimonio empresarial; incluso entre el patrimonio afecto a la actividad empresarial del grupo (actividad de riesgo) y aquél no afectado; $y$, además, confundir las cuentas de la empresa con las de la familia. Por otra parte, surgen problemas sobre la política de retribución de los miembros de la familia que trabajan en la empresa, ya sea como directivos o como meros trabajadores no cualificados, en función de su necesidad y no en referencia a sus responsabilidades en la empresa, a los modelos del mercado de trabajo y a las posibilidades financieras de la empresa. Puede suceder, incluso, que una parte de los gastos económicos de la familia se encuentre financiada directamente por la empresa (confusión de monederos), o que la empresa reparta dividendos en función de las necesidades de la familia, olvidando las necesidades de capitalización o de financiación de la empresa.

A su vez, la estructura del accionariado, con el transcurso del tiempo, puede ser fuente de surgimiento de determinados problemas. En efecto, a partir de la segunda - de las siguientes generaciones la propiedad de la empresa se atomiza, lo que se traduce en mayores dificultades para la adopción de acuerdos $y$, por tanto,

${ }^{26}$ Neubauer y Lank (2003), p. 41.

27 Fernández-Tresguerres García (2002), pp. 89-90; Roca Junyent (2005), pp. 33 y ss.; LeaCh (1999), pp. 30 y ss.

Revista de Fomento Social 70 (2015) 
para el buen gobierno de la empresa. El decurso del tiempo y el incremento de los miembros de la familia conllevan la necesidad de afrontar la posible apertura de la empresa a socios no familiares. En este sentido, se corre el riesgo de producirse el cierre a ultranza de la empresa a este tipo de socios, lo que, en su caso, podría impedir el aporte de nuevas sinergias, de nuevo personal humano, normalmente de corte profesional, de nuevas tecnologías, productos o mercados útiles para el proyecto de futuro de la empresa, con la repercusión negativa que una política en tal sentido puede suponer para la empresa. Y, por último, el paso generacional supone la adopción de una adecuada planificación financiera y fiscal para evitar que las tensiones propias de los procesos sucesorios acaben finiquitando la aventura empresarial.

\subsection{Los dos grandes problemas de las empresas familiares: el buen gobierno y los procesos sucesorios}

El buen gobierno de la empresa familiar requiere una estructura societaria flexible que satisfaga las necesidades e intereses familiares de índole normalmente personalista y que, en consecuencia, tienden a entrar en contradicción con los principios societarios capitalistas que impregnan la regulación imperativa de nuestras sociedades mercantiles.

Sin embargo, el régimen de responsabilidad ilimitada, personal, subsidiaria y solidaria de los socios colectivos respecto de las deudas sociales (ex arts. 127 y 237 C. de c.) unido a la polivalencia funcional de la sociedad anónima y a la flexibilidad tipológica de la sociedad limitada ha conducido al total abandono de la sociedad colectiva como cauce organizativo válido para organizar jurídicamente cualquier empresa, incluidas por tanto las familiares. Estas, en efecto, han acabado por considerar a las sociedades de capital como la forma organizativa más óptima para la defensa de sus intereses. El problema estriba en que la naturaleza capitalista tanto de la anónima como de la limitada, en la configuración realizada por el legislador (recogida ahora en el Real Decreto Legislativo 1/2010, de 2 de julio, por el que se aprueba el Texto Refundido de la Ley de Sociedades de Capital, en adelante, LSC), conlleva necesariamente una postergación (en mayor - menor medida) de los elementos e intereses personales en pos de los intereses del capital y de los socios o accionistas. Esta jerarquía de intereses convierte a las sociedades de capital en instrumentos jurídicos no del todo apropiados para cobijar en su seno y dar respuesta oportuna a las necesidades, exigencias y desafíos que deben afrontar las empresas familiares para garantizar su permanencia y su competitividad en el panorama económico nacional e internacional. 
Pero, además, en la empresa familiar no sólo subyace el problema jurídico-empresarial del buen gobierno de tales empresas familiares; esto es, la cuestión de la creación y preservación de la organización del poder de gestión de la forma más óptima en el seno de una empresa familiar (sea cual fuere la forma jurídica adoptada). Al mismo tiempo, las empresas familiares han de afrontar un trascendente problema técnico-jurídico: la atribución de los bienes afectos a una empresa familiar al patrimonio de uno o más herederos o legitimarios ${ }^{28}$.

El paso generacional representa uno de los momentos más críticos en el desarrollo de las empresas familiares ${ }^{29}$. Sin duda alguna, el primer desafío al que se enfrentan las empresas familiares es la permanencia de la familia en una empresa (productiva) por más de cien años 0 , al menos, por cuatro generaciones ${ }^{30}$. Las estadísticas eco-

${ }^{28}$ VICENT CHULÁ (2000), pp. 29-30; para quien el Derecho debe, en primer lugar, asegurar que la sucesión hereditaria se realice sin traumas, de manera tal que se eluda la presencia en los órganos de decisión aquellos de miembros no preparados o cualificados o bien que puedan originar conflictos en la gestión (tales como cónyuges divorciados del miembro de la familia, hijos de divorciados, toxicómanos, ludópatas o viciosos del juego, incapaces, insolventes, etc.); sin perjuicio, no obstante, de que aquellos miembros excluidos tengan que ser compensados económicamente ex arts. 829 y 1056 CC (por ejemplo, a través de la adjudicación de las acciones de la sociedad familiar a los herederos que sean accionistas en el momento de elaborar el testamento, o bien concediendo voto plural en una sociedad de responsabilidad limitada, compensando con ventajas o privilegios en el dividendo y en la cuota de liquidación a los otros). Pero, en segundo lugar, el Derecho debe, también, ayudar a organizar el poder familiar en la empresa (esto es, en el seno de la sociedad o del grupo de sociedades). Eso se logra a través de fórmulas aristocráticas como la designación de testamentario universal, - bien a través de administrador fiduciario. Al administrador le son atribuidos los derechos políticos de las acciones o participaciones sociales, que se transmitirán después a los fideicomisarios, mientras que todos los herederos perciben los beneficios; o a través de la constitución de una sociedad regular colectiva con administrador estatutario (art. $132 \mathrm{C}$. de c.); o bien a través de fórmulas democráticas; es decir, mediante una comunidad indivisa de bienes impuesta por testamento, administrada por un Junta de comunidad familiar, por el tiempo que sea necesario para consolidar la empresa.

${ }^{29}$ Como afirmaron los profesores ARONOFF y WARD (1992), los tres problemas más importantes a los que se enfrenta una empresa familiar son la sucesión, la sucesión... y la sucesión.

${ }^{30}$ Esto es, la denominada teoría de la evolución (o involución) de las sociedades familiares enunciada por el profesor HUGHEs (2004). En la práctica, se observa que la preservación de la sociedad mercantil en el seno de la familia viene ligada a comportamientos humanos. El relevo generacional representa un proceso dinámico de una actividad de grupo que debe ser renovada y revitalizada en cada sucesiva generación para evitar la amenaza de la entropía. El patrimonio de una familia viene entregado y legado a los miembros de las generaciones futuras. Pero la verdadera riqueza de una familia consiste en el capital humano e intelectual de sus componentes. Al fin de preservar su riqueza, la familia deberá compartir en su seno valores comunes que deberán ser reafirmados y adoptados por cada generación sucesiva. Es más, al fin de preservar su riqueza, deberá además consensuar y adoptar un sistema de "family governance", a través del cual se pueda perseguir eficazmente tales valores comunes. El 
nómicas sobre longevidad de empresas familiares nos muestran la enorme dificultad existente en el momento sucesorio. Sólo en Europa tienen éxito entre el 10 y el 25\% de las operaciones de traspaso generacional y entre el 30 y el $40 \%$ en los Estados Unidos. Concretamente, el $61 \%$ de las empresas familiares son controladas por la familia en la primera generación, el $24 \%$ por familias de segunda generación, el $9 \%$ por terceras generaciones y el 13\% por la cuarta generación y el sólo el $6 \%$ por generaciones sucesivas. Se confirma así la famosa aseveración según la cual la primera generación crea, la segunda continúa y la tercera destruye ${ }^{31}$.

La mayoría de la literatura económico-empresarial se muestra unánime a la hora de afirmar que los procesos sucesorios únicamente pueden afrontarse con cierto grado de éxito si se planifica en vida del fundador $(y$, si es posible, en momento en que todavía la lucidez de sus decisiones no se vean aquejadas por el irremediable deterioro que, no siempre pero sí muy a menudo, provoca la senectud). La planificación del proceso sucesorio ha de tener como finalidad la elección del sucesor más óptimo, lo que conlleva una atribución de los activos empresariales, esto es, un verdadero proceso traditorio entre el fundador y el sucesor. Este proceso traditorio a realizar por el fundador a favor del heredero más adecuado tiene que ser reforzado y garantizado jurídicamente en el mayor grado que sea posible, evitando que se pueda poner en peligro el paso del testigo de las riendas de la empresa al delfín por el resto de herederos no elegidos o por la propia voluntad del fundador manifestada en un momento posterior (siempre que no se apoye en razones objetivas por la ineptitud manifiesta del delfín). A fin de evitar este fatal desenlace, el lobby empresa familiar ha venido reclamando la perfección del Derecho sucesorio; expresión eufemística que, en su versión más radical, ha de entenderse como exigencia de eliminación del sistema de legítimas, así como de cualquier otra limitación existente a la autonomía de la voluntad del testador.

objetivo de este sistema de "family governance" no deberá ser otro sino la promoción de la felicidad de cada uno de componentes singulares de la familia.

${ }^{31}$ Concretamente para los profesores NeUBAUER y LANK (2003), entre dos tercios y tres cuartas partes de las empresas familiares son vendidas por la familia fundadora durante la primera generación y solamente entre un $5 \%$ y un $15 \%$ continúan en la tercera generación en manos de sus descendientes. Como afirma el profesor Hughes (2004), la primera generación, en efecto, es aquélla que sin formación académica pero con muchas ideas y con muchas ganas de trabajar, logra acaparar un gran patrimonio manteniendo, eso sí, un estilo de vida frugal. La segunda generación es aquella que frecuenta la universidad, empieza a vestir bien, vive en la ciudad, va al mar o a la montaña los fines de semana, pero mantiene el statu quo creado por los padres. La tercera generación, en cambio, se instala en el lujo, despilfarrando el capital acumulado por las anteriores generaciones, de forma que logra que las siguientes generaciones vuelvan al duro trabajo cotidiano. Por desgracia se confirma el famoso aforismo: de mangas de camisa a mangas de camisa en tres generaciones. 


\section{Las empresas familiares y su estructura societaria}

\section{I. La autonomía societaria y la configuración "familiar" de las sociedades mercantiles}

Abordada la construcción conceptual de la empresa familiar, conviene efectuar, en último lugar, algunas reflexiones sobre aquellas instituciones de Derecho societario cuya regulación, quizás, deje un espacio suficiente a la autonomía privada para servir más eficazmente al objetivo principal del fundador de una empresa familiar: la mejora de su gobernabilidad y su transferencia "mortis causa" conservando la titularidad en el seno de la familia.

La cuestión tipológica en las empresas familiares es un problema que incide en una materia tan vital como puede ser su eficiencia económica y, por tanto, su subsistencia en el tiempo, resultando, además, determinante en el tránsito de una empresa de titularidad individual a una empresa de titularidad societaria, así como en la sucesión entre los miembros de la sociedad familiar ${ }^{32}$. Para una elección óptima del tipo societario más adecuado se debe tener en cuenta que el prototipo de empresa familiar se corresponde con aquella de mediana y pequeña dimensión, cuyos titulares se encuentran ligados entre ellos por vínculos de parentesco, teniendo además el deseo de consolidar en el tiempo tanto el disfrute de la empresa, como su titularidad en manos de la familia.

La acomodación en tipos sociales capital istas de realidades empresariales familiares no resulta una tarea fácil. Nuestro Derecho de sociedades adolece de cierto grado de inflexibilidad que dificulta la regulación de nuevas realidades empresariales no previstas por el legislador. Frente al modelo societario angloamericano, los sistemas latinos basados en la configuración legal de tipos sociales son poco eficaces a la hora de personalizar (o, en nuestro caso, familiarizar) la ponderación y regulación de las necesidades e intereses particulares, empresariales y personales de los socios. La autonomía de la voluntad, se dice, se encuentra muy cercenada en nuestro Derecho societario ${ }^{33}$.

Sucede, en efecto, que nuestro sistema tipológico societario prohíbe la creación de tipos distintos de los regulados por el Código de comercio y por diversas leyes

\footnotetext{
32 Rodríguez Artigas (2005), p. 388.

${ }^{33}$ Serrano Cañas (2010), pp. 152-160.
} 
especiales. Ante la imposibilidad de crear un nuevo tipo social para las sociedades familiares, cabe optar por un doble recurso: redactar cláusulas estatutarias atípicas que introduzcan particularidades propias de índole familiar en la regulación del tipo social elegido; o acudir a la regulación extrasocietaria de los intereses personales y societarios mediante el recurso a los pactos parasociales, al margen pues de la protección y eficacia jurídico-societarias atribuidas a los estatutos sociales.

Sobre la base de lo dispuesto en el art. 28 LSC, en los estatutos se pueden incluir además de las menciones mínimas exigidas con carácter legal, cualesquiera otros pactos o condiciones especiales que los socios fundadores juzguen conveniente establecer, siempre que no se opongan a las leyes ni contradigan los principios configuradores del tipo social elegido. En este sentido, la mayor flexibilidad del régimen jurídico de la SRL hace que el grado de autorregulación sea mucho mayor en este tipo social que en la SA ${ }^{34}$. Así, sin ánimo de ser exhaustivo, cabe mencionar las siguientes cláusulas estatutarias admitidas ${ }^{35}$ :

1. La creación de determinadas clases de acciones o participaciones privilegiadas, que distribuyan de forma desigual los distintos derechos políticos y económicos atribuibles a los socios.

2. La restricción de la transmisibilidad de acciones o participaciones.

3. La atribución de un poder representativo irrevocable a determinados miembros de la familia para ejercer el voto en la Junta, así como el establecimiento de requisitos especiales para optar al nombramiento como administrador social.

4. El establecimiento de prestaciones accesorias (fundamentalmente la de cumplimiento del protocolo familiar).

5. La inserción de cláusulas de separación y de exclusión de los socios ${ }^{36}$.

\footnotetext{
${ }^{34}$ No obstante, no siempre resulta ser cierta la pretendida mayor flexibilidad de la sociedad de responsabilidad limitada ya que ésta remite en muchos aspectos de su regulación a la SA, hasta el punto de que algún sector doctrinal considera que en realidad constituye una forma particular de SA. NAVARRO MATAMOROS (2009), pp. 45 ss.

${ }^{35}$ Fernández del Pozo (2008), pp. 110 ss.

${ }^{36}$ En este sentido, existe una ardua polémica entorno a la admisibilidad o no de la separación "ad nutum" del socio, esto es, la consagración como derecho estatutario de separación la simple denuncia del socio sin que sea necesaria demostrar la existencia de justa causa. VeLA TORRES (2011), p. 3.
} 
Sin embargo, la autonomía de la voluntad a la hora de elaborar nuevas cláusulas societarias encuentra serios obstáculos, unos de naturaleza jurídica y otros de índole fáctica, que impiden su correcta implantación en el seno de las sociedades mercantiles familiares. Jurídicamente, tales cláusulas como cualquier otra de naturaleza contractual deberán respetar las leyes imperativas, la moral y el orden público (según el art. $1255 \mathrm{CC}$ ); pero, además, no podrán contravenir el contenido imperativo del régimen legal de anónimas o limitadas (que no es poco), así como, allí donde la ley deja algún hueco a la autonomía de la voluntad, los famosos e indeterminados principios configuradores del tipo social elegido (art. 28 LSC).

Pese a esta libertad de configuración de los estatutos sociales, empero, existen límites fácticos que cercenan la libertad a la hora de configurar nuevas y atípicas cláusulas estatutarias. Nos referimos al doble control de legalidad que han de superar quienes quieran iniciar una actividad societaria. El sistema de inscripción registral requiere pasar primero por la notaría para después inscribir en el Registro mercantil los estatutos sociales, previa calificación positiva del registrador mercantil. He aquí que este doble proceso garantista obstaculiza la posibilidad de introducir en los estatutos cláusulas que se salgan de lo normal. Como consecuencia, se ha extendido la práctica de formular modelos de estatutos tipo o prerredactados (a modo, "mutatis mutandis", de condiciones generales de la contratación) en los que rara vez se introducen cláusulas estatutarias originales y novedosas, y cuando así sucede es harto infrecuente que el registrador mercantil dé su brazo a torcer y las califique de forma positiva. Es más, la doctrina de la DGRN, en ocasiones, resulta demasiado rigurosa y apegada a la letra de la Ley, lo que dificulta y retrasa la incorporación de nuevas cláusulas estatutarias (como por ejemplo las cláusulas de arrastre -"tag long" ○ "drag along"-) utilizadas con normalidad en los países de nuestro entorno ${ }^{37}$.

Nos queda, pues, el auxilio de los pactos parasociales como último recurso para familiarizar los tipos societarios. Estos son pactos privados, contratos, realizados por todos o algunos de los socios para regular todos o algunos de los aspectos de la vida societaria, esto es, las relaciones entre los socios y la sociedad, entre los socios entre sí y entre éstos y los terceros. Con ellos se pretende completar, concretar o modificar, en sus relaciones internas, las reglas legales y estatutarias que rigen la vida de la sociedad. Son los famosos "pactos reservados" que hasta hace bien poco (concretamente por la Ley de Sociedades Anónimas de 1951, en su art. 6) eran considerados nulos. En la actualidad, sin embargo, se admite

\footnotetext{
${ }^{37}$ Navarro Matamoros (2009), pp. 40 ss.
} 
su validez pero sin otorgarles eficacia jurídico-societaria, en el sentido de que los pactos que se mantengan reservados entre los socios serán válidos pero no oponibles a la sociedad (art. 29 LSC).

Su uso adquiere una notable relevancia a la hora de personalizar un tipo societario capitalista, al presentar la enorme virtualidad de su absoluta flexibilidad y disposición ${ }^{38}$. Se puede, en efecto, pactar cualquier obligación con el único límite de lo dispuesto en el art. 1255 CC (las leyes, la moral y el orden público). La única desventaja es el problema de su eficacia (o, "rectius", en expresión inglesa, el de su "enforcement"). Los pactos parasociales, como todo contrato, tienen fuerza de ley entre las partes contratantes (art. 1901 CC). Tales pactos, por tanto, sólo vincularán a los socios que los hayan suscrito, pero no vincularán a los futuros socios, ni a la sociedad, ni a los terceros.

\subsection{Un específico pacto parasocial para las empresas familiares: Ios protocolos familiares}

Pese a que la LSC otorga un amplio margen a la autonomía de la voluntad (nada desdeñable, a decir verdad, aunque desde ciertas posiciones doctrinales apegadas al análisis económico del Derecho se empecinen en afirmar lo contrario) para personalizar la estructura y organización de las sociedades de capital, se ha generalizado la creencia errónea de que la regulación societaria (tanto la establecida por la LSC, como la que pueden llevar a cabo los socios a través de la configuración estatutaria de la sociedad) resulta inconveniente, insuficiente e ineficaz para la consecución de la necesaria personalización ("rectius" familiarización) de la realidad empresarial.

En esta tesitura entre lo estatutario y lo parasocietario, desde hace unas décadas, las empresas familiares han optado por desarrollar las virtudes de los pactos parasociales elaborando un concreto pacto parasocial o "shareholders agreement": los protocolos familiares ${ }^{39}$. Se trata de contratos entre los socios y los miembros de la familia (creados a modo de constitución político societaria de la familia) por los que se regulan las relaciones entre la familia, la empresa y la sociedad. En efecto, existe práctica unanimidad doctrinal en cuanto a la conveniencia de

38 Paz-Ares (2003), pp. 19 y ss.; idem (2005), pp. 711 y ss.; MAdRIDejos Fernández (1996), pp. 187 y ss.; Miquel Rodríguez (1998), pp. 10 y 310-311; Campins (2002), pp. 1688-1689 y 1704 Y ss.

${ }^{39}$ Fernández del Pozo, l. (2008), pp. 110 y ss.; Serrano Cañas (2013), pp. 37 y ss. 
la elaboración de un protocolo familiar - a modo de pacto parasocial, fuera, por tanto, de la configuración estatutaria prediseñada por el legislador- como medio para alcanzar el buen gobierno de las empresas familiares y superar los posibles obstáculos jurídicos que traen causa de la configuración tipológica de las sociedades de capital.

Este protocolo no es sino un acuerdo de voluntad ("tertium genus" entre un pacto de caballeros y un verdadero contrato) celebrado, consensuado y aprobado por la unanimidad de todos los miembros de una familia en el que se sustancia un verdadero código de conducta (al estilo de los códigos de autodisciplina o "best practices" de las sociedades anónimas cotizadas). El protocolo familiar se configura, así, como aquel documento contractual que delimita el marco de desarrollo y las reglas de actuación y comportamiento entre la familia, la empresa y la organización societaria en que ésta, normalmente, se desarrolla ${ }^{40}$.

El protocolo familiar es, en realidad, una mera herramienta jurídica cuya finalidad es la de promover en la familia un sentido de pertenencia a una finalidad o interés superior (la explotación de una actividad empresarial como medio para la defensa de las necesidades familiares), al mismo tiempo que se condiciona el comportamiento económico empresarial a las exigencias y necesidades de los miembros de la familia. La finalidad del protocolo es la de disciplinar y solucionar los conflictos específicos que surgen en las relaciones entre los miembros de la familia, la sociedad mercantil y la gestión y la organización empresarial; a la vez que intenta conseguir y asegurar la continuidad de la empresa de una manera eficaz, garantizando la permanencia de la empresa en el seno de la familia y viceversa, esto es, garantizando la permanencia de la familia en el seno de la empresa ${ }^{41}$. Por tal razón, el protocolo participa más de las técnicas del "management" que de fundamentos jurídicos.

El protocolo básicamente consiste en una mera declaración de intenciones, de pautas generales de actuación que, a modo de un pacto entre familiares, se formalizan en un documento mediante el cual se pretenden la regulación de los conflictos presentes y futuros entre la familia y la empresa, la propiedad y la gestión de una concreta sociedad o grupo de ellas. El protocolo, en suma, es un documento educativo cuya finalidad confesada es la de introducir en la familia una cultura

${ }^{40}$ Serrano Cañas (2013), p. 42.

${ }^{41}$ Sánchez-Crespo Casanova, Bellver Sánchez y Sánchez Sánchez (2005), pp. 25 y ss.; Serrano Cañas (2010), pp. 152-160, idem, (2013), pp. 41 y ss.

Revista de Fomento Social 70 (2015) 
empresarial y el fomento de un efecto psicológico: la conciencia de pertenecer a una familia empresaria.

Como se desprende de este marco psicológico en el que se desenvuelven los protocolos familiares, no todo su contenido goza de carácter jurídico, originador de obligaciones jurídicas. En verdad, pese a ese aspecto educativo, el protocolo familiar es algo más que un mero código de conducta. Constituye un verdadero negocio jurídico atípico: un negocio jurídico complejo, compuesto de varios negocios jurídicos simples 0 , incluso, por pactos que carecen de eficacia jurídica alguna. En él, se pactarán cláusulas que directamente no se pueden ejecutar (o no dan lugar a una verdadera obligación jurídica), o cláusulas que no necesitan ejecución porque directamente son fuerza de ley entre las partes contratantes; $y$, por último, cláusulas que necesitan un desarrollo ulterior para su completa eficacia. A pesar de todo, en la práctica incluso el contenido moral suele cumplirse.

Allí donde la empresa familiar revista un ropaje societario, el protocolo familiar goza de naturaleza jurídica equivalente al "shareholders agreement" de la Close Corporation en los EE.UU., esto es, el protocolo familiar encierra en sí mismo un verdadero pacto parasocial cualificado, en el sentido de que no sólo organiza y coordina las relaciones entre los socios familiares y la sociedad mercantil que da forma jurídica a la empresa familiar, sino que pretende la regulación de las relaciones entre la familia, la sociedad y la empresa que convergen en un fin común superior: la consecución de un interés (empresarial y societario) familiar. A tal fin, es posible (y recomendable) insertar de forma indubitada en el protocolo familiar los objetivos perseguidos por el fundador-empresario, creando órganos asesores y de armonización de conflictos entre la familia y la empresa: el Consejo Familiar; estableciendo las directrices a seguir por los miembros de la familia que sean, a su vez, socios de la sociedad mercantil organizadora de la empresa familiar; pero, también, que sean trabajadores de la empresa familiar.

El protocolo familiar como instrumento favorecedor de la administración de una empresa familiar no está exento de problemas jurídicos. Dejando a un lado la cuestión de su contenido, los protocolos familiares presentan, fundamentalmente, el hándicap de discernir y determinar en qué medida gozan de fuerza jurídica vinculante entre las partes. Es indudable que el protocolo familiar, al menos en su versión menos fuerte (esto es, considerado como un mero pacto de caballeros), tiene una indubitada fuerza moral que empuja o impulsa a las partes a cumplir la palabra dada y, quizás, sea ésta su virtud más destacable (cuando no la única). La cuestión fundamental estriba en si, además de esta fuerza moral, su cumplimiento pueda ser efectivamente exigido no sólo "inter-partes", sino frente a la propia 
sociedad mercantil o, incluso, frente a terceros. A ello se une la necesidad, además, de especificar cuáles sean los instrumentos legales existentes más eficaces para reforzar el cumplimiento y exigibilidad del contenido del protocolo. Se trata, en fin, de determinar si el protocolo familiar -cuando la empresa familiar se articule bajo una estructura societaria- tiene o no, más allá de su (posible) naturaleza contractual, naturaleza societaria.

El empleo de protocolos familiares no sólo se recomienda como solución a los problemas que puedan surgir en el seno de la familia y en relación con la empresa, sino que puede contribuir de manera sustancial a la supervivencia de la empresa familiar, preparándose apriorísticamente para afrontar los retos inherentes a los procesos de cambio intergeneracionales. Sin embargo, su eficacia en este punto dista mucho de ser satisfactoria, puesto que choca de pleno con la prohibición de los pactos sucesorios, así como por el hecho de configurar al testamento (que, además, es siempre revocable) como el único instrumento jurídico ideado por el legislador a través del que una persona puede disponer de sus bienes para el momento posterior al de su fallecimiento.

El protocolo familiar, en suma, institucionaliza a la empresa familiar, la llena de contenido y la preconfigura jurídicamente. Por tal razón, en el protocolo se intenta abordar todas las materias concernientes a la empresa familiar y al interés familiar, coordinando las sinergias empresariales y familiares y planificando todos los aspectos que pueden incidir en la reorganización de la empresa familiar: la gestión empresarial, la fiscalidad, las cuestiones estrictamente familiares, la configuración jurídica de la sociedad mercantil, etc.

El legislador español ha otorgado máxima eficacia jurídica a estos específicos pactos parasociales. Y ello a través de la promulgación del Real decreto 171/2007, de 9 de febrero, regulador de la publicidad de los protocolos familiares. Por medio de este Real decreto se intenta abrir el Registro mercantil a los protocolos familiares, como medio de reconocimiento de su eficacia jurídica "erga omnes".

\subsection{El «Drei Stufen Modell» como punto de partida}

Para dar una más adecuada respuesta a la cuestión tipológica (esto es, a qué tipo social resulta más apropiado e idóneo para organizar una empresa familiar) puede ser de interés un acercamiento a la división de los tipos societarios capitalistas sobre la base de los modelos de organización-empresarial que subyacen en ellos. En los años cincuenta, el profesor AsCARELL realizó una primera clasificación de la realidad económica que encerraba la estructura societaria de las sociedades 
anónimas sobre la base de tres tipos diversos: la gran sociedad anónima abierta con acciones cotizadas en Bolsas de valores y difundidas entre centenares (si no miles 0 , incluso, centenares de miles) de accionistas y con cifras millonarias de capital social; las sociedades anónimas con mediano o pequeño nivel empresarial y con una mediana dimensión subjetiva de socios, que es el tipo más frecuentemente visualizado por la doctrina tradicional y la realidad contemplada por las legislaciones sobre sociedades; $y$, por último, las sociedades sustancialmente unipersonales ${ }^{42}$. Esta división tripartita se encuentra en la base de una de las contribuciones más relevantes al Derecho societario de los últimos decenios. Nos referimos a la propuesta del "Drei Stufen Modell" elaborada por los profesores ALBACH y LUTTER ${ }^{43}$, seguida incluso más allá del Atlántico ${ }^{44}$, según la cual se pueden distinguir tres grupos de sociedades capitalistas:

$1^{\circ}$. La gran sociedad de capital bolsística, esto es, aquélla que cuenta con un número amplísimo y disperso de socios, natural y racionalmente apáticos y desatentos a la vida societaria y sólo interesados en la cotización de sus valores.

$2^{\circ}$. La sociedad de capital abierta, es decir, aquélla que goza de un círculo abierto de socios activos, en la cual se da el clásico conflicto entre mayoría y minoría, cuyas posiciones e, incluso, intereses son defendidos activamente en los órganos deliberantes y de control societario, y cuyas acciones no cotizan en los mercados financieros, sino que, por el contrario, acuden al denominado mercado secundario de capital -"geregelter Markt"-; tal tipo social se corresponde, por tanto, con el modelo legal de sociedad anónima, tal como aparece tipificado en las legislaciones latinas ${ }^{45}$.

$3^{\circ}$. Y, por último, la sociedad de capital de base personalista -" close corporations", según la terminología anglosajona ${ }^{46}$-, cuya naturaleza capitalista (según la cual

42 AsCARELI (1959), pp. 995 y ss., donde añade que esta última "ora è modesta ora però concentra un fortissimo patrimonio; ora ha come socio una persona fisica, ora invece una societò; risponde in alcuni rari casi all'intento dell'esercizio del commercio con responsabilità limitata; spesso si coordina con problemi fiscali o con esigenze di decentramento aziendale». Esta idea se puede encontrar en el pensamiento de otros importantes autores como es el caso del profesor GIRÓN TENA (1989), pp. 923 y ss.

${ }^{43}$ Albach, Corte, Friedewald, LUtTer y Richter (1988), pp. 36 y ss.

${ }^{44}$ EISENBERG (1976), pp. 19 y ss.

${ }^{45}$ Ascareul (1959), p. 997.

${ }^{46}$ En los Estados Unidos, por "Close Corporations" se entiende aquella sociedad anónima cerrada, no cotizada, con restricciones a la libre transmisibilidad de las acciones, y cuyos accionistas son con- 
la condición de socio sólo se adquiere a través de la correspondiente aportación al capital social) se encuentra en cierto modo minimizada por la importancia que se pretende otorgar al "intuitu personae". Nos encontramos, pues, ante sociedades compuestas generalmente por un número reducido de socios, que encuentran su causa última constitutiva en la existencia de un vínculo particular de confianza recíproca, por el que las cualidades personales de cada uno de los socios adquieren especial relevancia para la consecución de los fines comunes. Este número reducido de socios convierte a la sociedad de capital cerrada en una verdadera comunidad de trabajo (al estilo de las sociedades colectivas), de tal forma que los propios socios participan activamente en el desarrollo del objeto social, desempeñando además, y frecuentemente, el cargo de administradores sociales. Naturalmente, el elemento personal conlleva, como una manifestación más, la exclusión (o una mayor y más severa limitación) de la circulación de las cuotas societarias en los mercados de capitales.

Estos tres modelos de organización societaria deben ser compatibles con los distintos tipos societarios jurídicamente tipificados por las diversas leyes de sociedades mercantiles: sociedad colectiva, comanditaria simple o por acciones, anónima, limitada, etc. En este sentido, los profesores ALBACH y LUTTER proponían una profunda reforma de la tipología societaria, en el sentido de que o bien la legislación societaria consintiese a todas las empresas societarias operar bajo una misma categoría general de sociedad por acciones que contase con una regulación altamente flexible, susceptible de dar cobijo a tipos organizativos muy diversos (esto es, adoptar un sistema unitario, como acontece en el mundo anglosajón), o bien, por el contrario, operar al modo de los sistemas latinos, utilizando y reduciendo la tipología existente a dos formas jurídicas diferenciadas entre sí: la sociedad anónima (con una regulación apropiada sólo para las grandes corporaciones empresariales) y la sociedad de responsabilidad limitada (reducida al tipo común para pequeñas y medianas empresas) ${ }^{47}$.

siderados propietarios y ejercitan efectivamente el poder de gestión, y en la que la legislación de los diversos Estados consiente importantes derogaciones al régimen imperativo legal a través de pactos estatutarios $\mathrm{o}$, incluso, parasociales (Wisconsin) o consiente levantar el velo de la personalidad jurídica imputando responsables a los accionistas en caso de incumplimiento de normas formales, confiriendo a los tribunales poderes excepcionales para disolver la sociedad, imponer la compra de las acciones de un accionista, ordenar el pago de dividendos o separar a los administradores o nombrar administradores judiciales provisionales, en caso de fraude o culpa grave en la gestión societaria.

${ }^{47}$ Fernández de la Gándara (1994), pp. 35 y ss.; Esteban Velasco (1994), pp. 13 y ss. 


\subsection{La sociedad de responsabilidad limitada como forma óptima de organi- zación de la empresa familiar}

La cuestión sobre la forma jurídica más óptima para organizar jurídicamente a las empresas familiares debe resolverse a partir de la realidad empresarial subyacente. Las sociedades mercantiles de base familiar constituyen -en la mayor parte de las veces, si bien de forma no exclusiva- una modalidad específica de empresa, que necesita un tipo societario de capital de naturaleza personalista, donde se pueda conjugar la estructura corporativa típica de una sociedad capitalista, con elementos de personificación ("rectius", de familiarización) $)^{48}$. En este sentido, es posible erigir a la sociedad de responsabilidad limitada como el tipo societario más idóneo para organizar jurídicamente una empresa familiar ${ }^{49}$, al menos en los sistemas societarios latinos, sobre todo cuando las empresas familiares sean de pequeñas o medianas dimensiones.

Es lo cierto, sin embargo, que la regulación societaria interna de empresas familiares se aproxima al sistema que gozan los socios de sociedades colectivas. Además, el tipo societario elegido debe ser capaz de atribuir a los socios familiares (fundamentalmente al fundador) el derecho de elegir a los administradores o de vetar algunas operaciones empresariales que a su juicio sean demasiado arriesgadas o contrarias al espíritu familiar. Al mismo tiempo, resultará de interés para las empresas familiares la inaplicación de un principio societario basilar como es la igualdad de trato de los socios ${ }^{50}$, otorgándoles derechos económicos y políticos no

${ }^{48}$ Surge entonces el problema de la determinación de los principios configuradores del tipo societario (problema análogo al de la autonomía estatutaria y contractual y sus límites en el Derecho societario). La autonomía estatutaria no viene concedida de forma absoluta, sino que cuenta con unos determinados límites, dentro de los cuales debe ser ejercitada. Fundamentalmente, el más importante viene representado por el respeto del principio de la tipicidad, lo que conlleva el respeto de las características esenciales del tipo elegido, de forma que la autonomía estatutaria no podrá nunca desnaturalizarlo. Por tanto, la SRL, aun pudiéndose aproximar tanto al modelo de las sociedades personalistas como al de la sociedad capitalista por excelencia (la SA), deberá conservar los elementos fundamentales de toda SRL. Por otra parte, un segundo límite a la autonomía privada estriba en la propia regulación imperativa. En efecto, el estatuto legal de los diversos tipos societarios viene constituido por un sistema de normas cogentes y disposiciones dispositivas que establecen el ámbito natural de la autonomía privada societaria. VIERA GONZÁlez (2002), pp. 39 y ss.

${ }^{49}$ Cottino (1988); RodríGuez Artigas (2005), p. 389.

${ }^{50}$ En este sentido, conviene advertir que la Ley $3 / 2009$, de 3 de abril, de Modificaciones Estructurales de las sociedades mercantiles ha introducido en la Ley de Sociedades Anónimas un nuevo art. 50 bis intitulado precisamente lgualdad de trato, por el cual, La sociedad deberá dar un trato igual a los 
proporcionales a las efectivas aportaciones de capital efectuadas, sino en virtud de las necesidades familiares, lo que equivale a decir, merced a las aptitudes $y$ cualidades personales de cada socio familiar $\mathrm{o}$, mejor aún, por la conveniencia al interés familiar, según lo entienda y lo interprete en cada momento el fundador ${ }^{51}$.

En suma, se hace necesario construir una organización acentuadamente personalista en la que forma (organización societaria) y sustancia (empresa familiar) puedan convivir, evitando forzar la normativa y la racionalidad legislativa societaria para una mejor satisfacción de los intereses en juego o, al menos, una coordinación de tales intereses más acorde con la naturaleza armónica y afectiva propia de las relaciones familiares pero que, al mismo tiempo, gocen de la necesaria seguridad jurídica para poder resolver los posibles y futuribles conflictos entre los socios. Vista esta necesidad, el tipo social sociedad de responsabilidad limitada, por sus cualidades y características inherentes, por el equilibrio que hace el régimen de la SRL (contenido ahora en la Ley de Sociedades de Capital) entre normas imperativas y dispositivas, por el peso de la tradición, etc., es el más apropiado para configurar una empresa familiar.

Con todo, este tipo social no es el único posible, ni el único dable en la realidad que nos rodea. Así, la sociedad anónima, a través de la posibilidad de limitar la libre transmisión de acciones, entre otros pactos estatutarios o parasociales, consiente una cierta adaptación a las exigencias de las empresas familiares ${ }^{52}$-siendo así que es norma y praxis general para las empresa familiares de grandes dimensiones, sobre todo cuando deban acudir a los mercados de valores, por cuanto que el tipo sociedad anónima resulta obligatorio.

Sin embargo, en la idealización legislativa societaria, como hemos evidenciado, la sociedad de responsabilidad limitada es concebida como sociedad constituida

accionistas que se encuentren en condiciones idénticas, que en la LSC aparece formulado en el art. 97. Al mismo tiempo, como consecuencia de la Ley $25 / 2011$, de 1 de agosto, de reforma parcial de la Ley de Sociedades de Capital, se ha añadido un nuevo artículo 514, dentro del Título XIV, destinado a reconocer el principio de igualdad de trato en el seno de las sociedades anónimas cotizadas, por mor del cual, las sociedades anónimas cotizadas garantizarán, en todo momento, la igualdad de trato de todos los accionistas que se hallen en la misma posición, en lo que se refiere a la información, la participación y el ejercicio del derecho de voto en la junta general.

${ }^{51}$ Después de todo, los hijos pueden esforzarse un poco para beneficiarse del trabajo y de los resultados que los padres han obtenido.

${ }^{52}$ Rodríguez Artigas (2003), p. 19. 
normalmente por sujetos con características tales que no pueden ser cualificados como meros inversores, pero sí como fuertemente interesados en la gestión empresarial, de tal manera que se consigue gozar del privilegio de la responsabilidad limitada (al igual que en las sociedades anónimas) sin renunciar al poder de gestión (como si de una sociedad personalista se tratase). El legislador ha diseñado, pues, una disciplina para las sociedades de responsabilidad limitada en donde la autonomía estatutaria desarrolla un rol importantísimo, limitado sólo por la tutela de los terceros, en general, y de los acreedores sociales en particular. Así, la sociedad de responsabilidad limitada se configura como un tipo social caracterizado por una significativa y acentuada elasticidad, fundamento de las consideraciones personales de los socios, a los que se les confiere una amplia autonomía estatutaria a la hora de delinear los ejes organizativos de la sociedad. Su regulación jurídica consiente que la autonomía patrimonial societaria sea compatible con una regulación organizativa flexible, hasta el punto de poder ser modelada generalmente en clave personalista, según un modelo organizativo más cercano a las sociedades personalistas. La amplia autonomía estatutaria significa, pues, amplia elección para los socios de determinar las reglas de "governance". La LSC establece, en efecto, un modelo podríamos decir supletorio (o de "default"), sólo aplicable allí donde los socios no hayan establecido algo distinto en los estatutos. La SRL se convierte así en un modelo societario a mitad de camino entre el modelo capitalista por excelencia (esto es, el modelo de la SA) y el de las sociedades personalistas ${ }^{53}$. En la SRL, los socios gozan de un ámbito real de libertad para autorregularse, pudiendo modelar la "corporate governance" de la sociedad, haciendo de ella un tipo más personalista o, si se desea, un tipo más capitalista, según las exigencias específicas de la realidad empresarial subyacente.

En efecto, los socios-fundadores encuentran en la regulación de la SRL todo un conjunto de ventajas organizativas ${ }^{54}$. En primer lugar, el tipo legal de SRL hace posible la personalización de la organización societaria, incorporando en los propios estatutos pactos familiares particulares que, en caso contrario, deberían permanecer en el ámbito parasocial, es decir, fuera de la protección del Derecho societario $^{55}$. En segundo lugar, el régimen de la SRL admite la posibilidad de

${ }^{53}$ Galgano (1984), p. 453.

${ }^{54}$ Vicent Chulá (2000), pp. 33-34; Rodríguez Artigas (2003), p. 20.

${ }^{55}$ En efecto, especialmente pueden incorporarse en pactos parasociales, por ejemplo, un sistema desigual de voto según el cual la mayoría de la asamblea corresponda en cada momento, mediante un sistema de voto múltiple, a aquellos miembros de la familia que reúnan determinados requisitos establecidos por un protocolo familiar, y transcritos en estatutos sociales, para asumir la gestión empresarial. 
estatuir restricciones a la libre transmisibilidad de las participaciones sociales, incluyendo expresamente la prohibición por cinco años o permanentemente (si viene acompañado del derecho de separación de la sociedad en cualquier momento $)^{56}$. Asimismo, existe una importante simplificación organizativa y una significativa reducción de los costes de funcionamiento ${ }^{57}$; a lo que se añade una gestión muy flexible, una mayor agilidad en la adopción de decisiones y un mayor control de la Junta general sobre los administradores ${ }^{58}$. Por otra parte, existe una mayor facilidad a la hora de afrontar la desinversión o la separación/exclusión del socio, pudiéndose estatutariamente añadir nuevas causas de exclusión, como podrían ser las derivadas de procesos de fusión, cambio de la rama familiar titular del control, separación/exclusión de las funciones administrativas o directivas, necesidades familiares según los objetivos definidos en protocolos familiares o en estatutos sociales ${ }^{59}$. Además, es posible incluir cláusulas estatutarias de opción de venta a favor de socios o de la sociedad, en caso de incurrir en determinadas circunstancias; o ampliar las causas de exclusión de socios, en función del posible contenido del protocolo familiar.

A pesar de que no parezca posible hablar de un «tipo ideal» de sociedad de responsabilidad limitada, si existen ciertas características tipológicas. Así, la SRL aparece como una sociedad en cuyo seno conviven elementos heterogéneos -capitalistas unos, personalistas otros- combinados en forma desigual por los legisladores en cada momento histórico.

${ }^{56}$ Art. 108 LSC, cláusulas estatutarias prohibidas.

${ }^{57}$ A título de ejemplo, vid. art. 173.2 LSC, convocatoria de la Junta general (objeto de modificación merced a la Ley 25/2011), por el cual

los estatutos podrán establecer que la convocatoria se realice mediante anuncio publicado en la página web de la sociedad o por cualquier procedimiento de comunicación, individual y escrita, que asegure la recepción del mismo por todos los socios en el domicilio designado al efecto o en el que conste en la documentación de la sociedad. En el caso de socios que residan en el extranjero, los estatutos podrán prever que sólo serán individualmente convocados si hubieran designado un lugar del territorio nacional para notificaciones. Con carácter voluntario y adicional, la convocatoria se podrá publicar en uno de los diarios de mayor circulación en la provincia en que esté situado el domicilio social.

${ }^{58}$ Art. 161 LSC, donde se recoge la competencia de la Junta general de sociedades de responsabilidad limitada para impartir instrucciones al órgano de administración o someter a autorización la adopción por dicho órgano de decisiones o acuerdos sobre determinados asuntos de gestión.

${ }^{59}$ Art. 346 ss. LSC.

Revista de Fomento Social 70 (2015) 
En conclusión, la SRL se nos presenta como un tipo social polivalente y polimorfo, caracterizado por una estructura organizativa de geometría variable, dentro de los dos límites constituidos por un modelo que podríamos denominar como sociedad

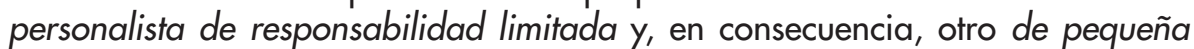
sociedad anónima, idónea para asumir los caracteres de un tipo puente entre las sociedades personalistas y las capitalistas. Podríamos, por tanto, afirmar que, por tratarse de un tipo societario de naturaleza híbrida, de carácter cerrado y régimen jurídico flexible, se nos presenta como el tipo ideal para ser adoptado por las empresas familiares ${ }^{60}$.

\section{Bibliografía}

Albach, H.; Corte, C.; FrIedewald, R.; LUTter, M. y Richter, W. (1988), Deregulierung des Aktienrechts: Das Drei-Stufen-Modell.

AlONSO EsPINOSA, F. J. (2012), «La empresa familiar como problema», RDM, núm. 283, en documento Westlaw, BIB 2012/749.

ARONOFF, C./ WARD, J. (1992), «Family Business succession: The final test of greatness», Family Business Leadership Series, núm. 1992.

AsCARELI, T. (1959), «Tipologia delle società per azioni e disciplina giuridica», en Riv. Soc., pp. 995 y ss.

Astrachan, J. H.; KLeIN, S. y SmyrniOS, K. (2000), «Th P-CE scale of family influence: a proposal for solving the family business definition problem», Family Business Review, 15 (1), pp. 45-57.

BERCOVITIZ, A. (1994), «Una visión crítica del Proyecto de Ley de sociedades de responsabilidad limitada», en AA.V.., La reforma de la sociedad de responsabilidad limitada, Consejo General de los Colegios Oficiales de Corredores de Comercio, Dykinson, Madrid, pp. 105 ss.

- (1998), "Noción y características de la sociedad de responsabilidad limitada», coord. BERCOVITZ, A., en AA.VV., La sociedad de responsabilidad limitada, Aranzadi, Madrid, pp. 97-98.

60 Un desarrollo pormenorizado de estas tres ideas puede verse en MiRANDA SeRRano y Pagador López (2002), pp. 180 y ss. 
BIRLEY, S. (2001), "Owner-manager attitudes to family and business issues: A 16 country study», Entrepreneurship in Theory and Practice, 26 (2), pp. 63-76.

BUONOCORE, V. (2003), La società a responsabilità limitata, en AA.VV., Manuale di diritto commerciale, dir. BOUNOCORE, Torino, pp. 361 y ss.

CERDÁ Alvero, F. (2004), «La empresa familiar: una cuestión relativa», en AA.W., El buen Gobierno de las Empresas Familiares, coord. VICENT CHULIÁ y otros, Aranzadi, Navarra, pp. 97 ss.

ChuA, J. H.; Chrisman, J. J. y Sharma, P. (1999), "Defining the Family business by behavior», Entrepreneurship a Journal of Practice \& Theory, Summer, pp. 19-39.

CORONA RAMÓN, J. F. (2005), «Introducción al análisis de la empresa familiar», en AA.VV., El patrimonio familiar, profesional y empresarial. Sus protocolos, Coords. GarRIDo Melero y Fugardo EstiviL, T. VI, Bosch, Barcelona, pp. 26 ss.

Cotrino, G. (1988), «La societò commerciale tra personalizzazione e spersonalizzazione», relazione al convegno su Imprenditorialità e diritto nell'esperienza storica, Erice, 22-25 de noviembre.

De Aguiar, E. (1998), Beneficios fiscales en la empresa familiar: patrimonio y sucesiones, La Caixa, Colección estudios e informes, núm. 13.

EISENBERG, M. A. (1976), The structure of the corporation, Boston-Toronto.

Esteban Velasco, G. (1994), «Sociedad anónima: principales aspectos y problemas de su regulación», RdS, núm. 2, pp. 13 ss.

FERNÁNDEZ DE LA GÁNDARA, L. (1994), «El problema tipológico: la consagración del modelo dualista», RdS, número extraordinario, pp. 35 ss.

FERNÁNDEZ del POZO, L. (2008), El protocolo familiar. Empresa familiar y publicidad registral, Civitas, Navarra.

Fernández GIMENO, J. P. (1999), Problemas de la transmisión de la empresa familiar, Tirant lo Blanch.

FeRnÁNDEZ-TResGuerRes GarcíA, A. (2002), «Protocolo familiar: un instrumento para la autorregulación de la sociedad familiar», RdS, núm. 19, pp. 89-113. 
Galgano, F. (1984), Diritto commerciale - Le società, Bologna, Cedam.

GarRido de Palma, V. M. (2005), "La familia empresaria ante el Derecho», en AA.VV., El patrimonio familiar, profesional y empresarial. Sus protocolos, Barcelona, Bosch, pp. 63-94.

Garrigues, J. (1976), Curso de Derecho Mercantil, T. I., Madrid.

Gersick, Davis, Maccollom y Lansberg (1998) Empresas familiares. Generación a generación, McGraw Hill

GIRÓN TenA, J. (1976), Derecho de sociedades, T. I, Madrid.

- (1989), «Las reformas varias, pendientes y andantes, de la sociedad anónima en España», La Ley, núm. 1, pp. 923 y ss.

Hughes JR., J. E. (2004), Family wealth - Keeping in the family: How Family Members and Their Advisers Preserve Human, Intellectual, and Financial Assets for Generations, New York, Bloomberg.

Iglesias PRADA, J. L. (1994), «El proyecto de Ley de sociedades de responsabilidad limitada y la empresa familiar», Revista General de Derecho, mayo, pp. 5.418 y ss.

KoteY, B. (2005), "Goals, management practices, and performance of family SMEs», International Journal of Entrepreneurial Behaviour \& Research, 11 (1), pp. 3-24.

LEACH, P. (1999), La empresa familiar, Barcelona, Granica.

Ministerio de ECONOMÍA (2003), Guía para la pequeña y mediana empresa familiar.

Miranda Serrano, L. M. y Pagador López, J. (2002), « ¿2articipaciones sin voto» Ensayo de una respuesta ("de lege data») para una cuestión societaria particularmente controvertida», RdS, núm. 18, pp. 180 ss.

Navarro Matamoros, L. (2009) «Simplificación y nueva tipificación en el Derecho societario español ante las nuevas tendencias del ámbito europeo», CEF, núm. 103-104, pp. 45 ss.

Neubauer, F./Lank, A. (2003), La Empresa Familiar. Cómo dirigirla para que perdure, Barcelona, Deusto. 
Paz-Ares, C. (2003), «El enforcement de los pactos parasociales», Actualidad Jurídica Uría \& Menéndez, núm. 5, pp. 19 ss.

- (2005), «Los pactos parasociales. Su eficacia», en AA.VV., El patrimonio familiar, profesional y empresarial. Sus protocolos, coord. GARRIDO MELERO, FUGARDO EstIVIL, T. IV, Barcelona, Bosch, pp. 728-740.

ROCA JUNYENT, M. (2005), «La empresa familiar en el ordenamiento jurídico interno y comunitario», en AA.VV., El patrimonio familiar y empresarial. Sus protocolos, coord. Garrido Melero, Fugardo Estivil, T. IV, Barcelona, Bosch, pp. 33 y ss.

RodríGUEZ ARTIGAS, F. (1993) «Régimen de las participaciones sociales en la sociedad de responsabilidad limitada. Disposiciones Generales. Artículo 9», en AA.VV., Comentario al régimen legal de las sociedades mercantiles, dir. URÍA, MENÉNDEZ y OuivencIA, Civitas, T. XIV, vol. $1^{\circ}$ A., pp. 224 y ss.

- (2003), «Sociedad de responsabilidad limitada y empresa familiar (notas sobre una reforma de la LSRL)», RdS, núm. 21, pp. 17 y ss.

- (2005), "La empresa familiar y las reformas de la ley de sociedades limitadas», en AA.V.., El patrimonio familiar, profesional y empresarial. Sus protocolos, coord. GARRIDO MeleRO y otros, pp. 388 y ss.

Rojo Ramírez, A. A.; Diéguez Soto, J. y López Delgado, P. (2011), «lmportancia del concepto de Empresa Familiar en investigación: utilización de la base de datos SABI para su clasificación", Revista de Empresa Familiar, vol. 1, núm. 1, pp. 54 y ss.

Roso, A. (1994), «La sociedad de responsabilidad limitada: problemas de política y de técnica legislativa», en AA.VV., La reforma de la sociedad de responsabilidad limitada, Consejo General de los Colegios Oficiales de Corredores de Comercio, Madrid, Dykinson, pp. 70-71.

Sánchez Álvarez, M. M. a (1997) «La prohibición de emitir obligaciones y otros valores negociables agrupados en emisiones (Comentario al artículo 9 LSRL)», RdS, núm. 9, pp. 65-75.

Sánchez-Crespo CaSAnova, A. J. (2000), La empresa familiar: Guía práctica de organización y funcionamiento. Desde el punto de vista familiar, civil-matrimonial y sucesorio-, societario y fiscal. Granada, Comares. 
Sánchez-Crespo Casanova, A. J.; Bellver Sánchez, A. y Sánchez y Sánchez, A. M. (2005), La empresa familiar: manual para empresarios. Claves legales para su correcta organización y su continuidad, Deusto.

Serrano Cañas, J. M. (2010), «Los protocolos familiares en el Real Decreto 171/2007. ¿̇Hacia la eliminación de los tipos sociales», en AA.VV., Morosidad, aplazamientos de pago y empresa familiar, dir. Font Galán y MiRANDA SeRrano, Sevilla, Academa Sevillana Notariado, pp. 149-205.

- (2013), El cambio generacional en empresas familiares, Madrid, Marcial Pons.

TAGIURI, R. y Davis, J. A. (1982), "Bivalent attributes of the family firm», Family Business Review, II (4), Cambridge, Mass., Working paper, Harvard Business School, pp. 329-339.

Tapia Hermida, A. J. (1996), "La financiación de la sociedad de responsabilidad limitada (con especial referencia a los arts. 9 y 10)», en AA.V., Derecho de sociedades de responsabilidad limitada. Estudio sistemático de la Ley 2/1995, coord. Rodríguez Artigas y otros, Madrid, Mc Graw Hill, T. I, pp. 112 ss.

Uría, Menéndez e lglesias Prada (1999), "Capítulo 42. La sociedad de responsabilidad limitada: Principios fundamentales», en AA.VV., Curso de Derecho Mercantil, coord. URía, MENÉnDEZ, T. I, Madrid, pp. 1050 ss.

Vela ToRres, P. J. (201 1), «El derecho de separación del socio en las sociedades de capital», en AA. VV., Documentos del VIII Congreso de Magistrados especialistas en Mercantil, Consejo General del Poder Judicial.

VICENT ChuLÁ, F. (2000), "Organización jurídica de la sociedad familiar», RdP, 2000-1, núm. 5, pp. 21 ss.

Viera González, A. J. (2002), Las sociedades de capital cerradas. Un problema de relaciones entre los tipos SA y SRL, RdS monografías, Navarra, Aranzadi. 